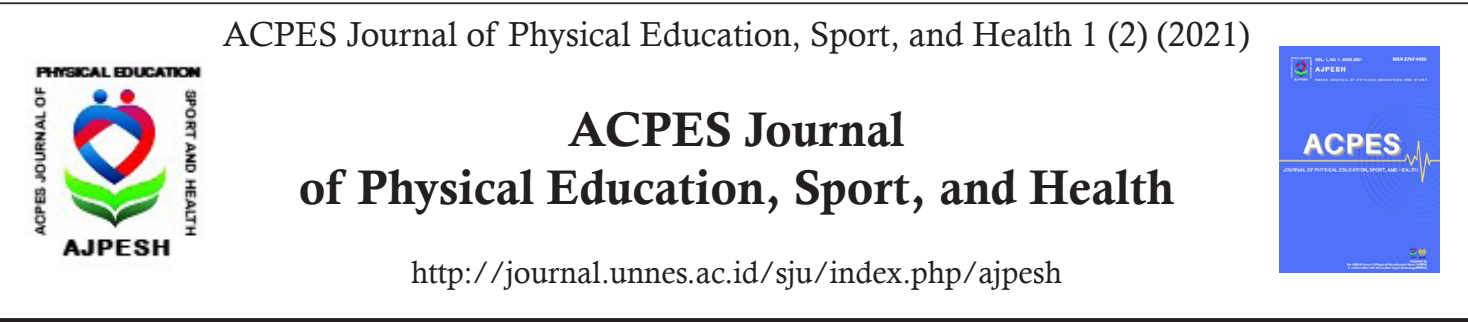

\title{
Examining the Relationship between Social Modelling and Physical Activities Involvement
}

\author{
Darlton-Ace C. Tero ${ }^{\bowtie}$, Corazon T. Biong, Juliet C. Tero \\ Mindanao State University- Iligan Institute of Technology, Philippines
}

DOI: https://doi.org/10.15294/ajpesh.v1i2.50755

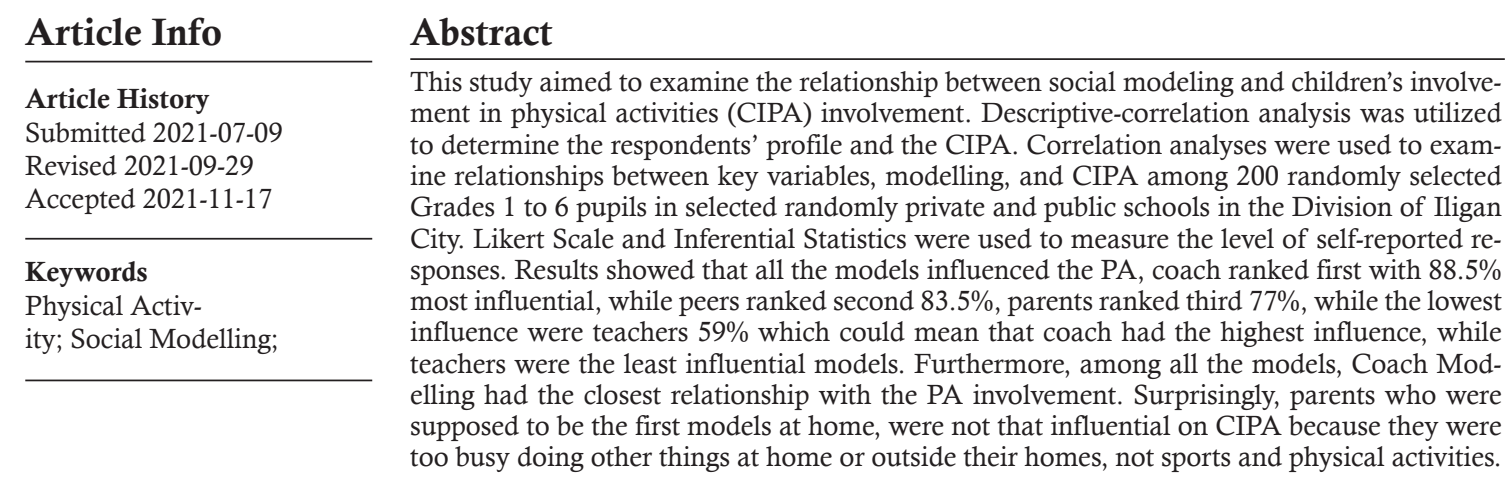

\section{INTRODUCTION}

Introduction In today's modernization and automation, life longevity is dwindling. This phenomenon is attributed to the unhealthy lifestyle of modern people. Life span is shortened due to sedentary habits of sitting in front of television sets instead of doing physical activities, riding in cars when going to near places instead of walking, thus people in present generation die as early as 50 years of age or even shorter. One major cause of health problems is physical inactivity modelled by the next generation, the children, from their parents, teachers, coach, and peer.

A growing body of research, delving on protective factors affecting children's and adolescents' lives, reveals that sports and physical activities can be modeled by the more knowledgeable other [MKO]: parent, teacher, coach (Peura et al., 2018; Acero et al., 2008), even friends or peers. Such modeling produces self-regulatory factors serving as central role-transformers of mental activities into academic skills (Coleman et al., 2008). Thus, children grow not only in physical and mental age but also socially with surroundings (Lopez et al., 2017), most importantly with parents as key roles in molding the young from birth to childhood, until adulthood. The MKOs and peers, like parents, also influence children's involvement in PA (Rickwood, 2015). Yet, parents should have the most influence among them all, as they are in the nucleus of the system in raising kids but confronted with key issues and questions regarding the nature and nurture of lifespan development, directly or indirectly affected by the environment (Feldman, 1981; Feldman, 2003), challenges that affect children's holistic

Correspondence Author:

Department of Physical Education, MSU-IIT, Iligan City, Philippines

e-ISSN 2797-0426

E-mail: darlton-ace.tero@g.msuiit.edu.ph 
development.

Since children's growth and development start mainly at home where parents provide their needs and serve as role models, the moment children go out from their homes, play with neighbors, and interact with the other $\mathrm{MKO}$, they are exposed to new things, learn mainly by observing others' behavior, attitudes, and outcomes of those behaviors as Bandura (1971) proposes that "most human behavior is learned observationally through modelling: from observing others. The individual constructs an idea of how new behaviors are carried out, such coded information guides the child's further actions that can affect both their current and future health (Allen et al., 2013). But, it is sad to note that in later years, children are further exposed to risks of tobacco, alcohol, gang activities, and sex at an early age, instead of engaging in wholesome and healthful PA. Physical inactivity or sedentary attitudes of sitting on the couch just to watch television, or enjoy the gadgets in browsing the net, plus overeating while staying stationary, are few of such observable practices which are deemed inferior (Sison, 2018).

While western countries were experiencing obesity as a threat to life, physical inactivity caused $6 \%$ of deaths globally as the $4^{\text {th }}$ leading risk factor (Moore et al., 2017), the Philippines had physically inactive Filipino adults $92.6 \%$ at risk in transport-related activities and heart problems with complications (Alberico et al., 2017) pointing out the value of MKO's direct or indirect influence on children's diet, and involvement in PA. Despite several promotions of PA, Efrat (2017) cites insufficient activity during elementary school years as the primary cause of health problems. Kids need to accrue PA with parents at age level or developmental stage in children's engagement, to what extent the other MKO can influence engagement, are pressing concerns (Ashford et al., 1993) augmented by the social climate of Information Age where children are hooked with gadgets at home or in school, instead of doing physical activities (Brewer, 2009).

Sad to say, some parents seem to have a 'no-care' attitude, guilty of neglecting their children, unmindful of the provisions of law to protect their children below eighteen (18) years of age or those over eighteen years but unable to fully protect themselves from abuse, neglect, cruelty, exploitation, or discrimination because of physical, mental disability, or unfavorable conditions (Pangalangan, 2011) referring to Villar's (2020) signed the bill on children's protection provided for in Republic Act 7610 's, focusing on psychological/psychiatric services, recreation, sports, and livelihood, for child's self-efficacy (Brewer, 2009) which Peura et al. (2018) citing prioritization of schoolchildren's health to build up self-efficacy (strong beliefs within the young that they could do worthwhile things in life). Parents become too busy working that they are unable to model sports and physical activities [PA] to their children. In schools, due to limited space, equipment, and facilities for PA, children's participation are curtailed. This condition is likely to worsen in the next decade to confront medical practitioners, physical educators, parents, and sports coach across races/ethnicities and nations, reported by the World Health Organization (Marmot et al., 2012; Allen, 2018); National Nutrition Surveillance Center (2009); and Heart Disease and Stroke Statistics (Benjamin-Neelon et al., 2018), include core health behaviors in smoking, physical activity, diet and weight; and health factors in cholesterol, blood pressure, and glucose control along with alarming risks not only among the elderly but in young children as well.

It was on this premise that this paper was conceptualized and developed to investigate the randomly selected 200 pupil-respondents' (Grades 1 to 6) engagement in sports and physical activities [PA] and the effects of parents, teacher, coach, and peer modelling on such engagement. Respondents were enrolled in public and private schools during the school year 2018-2019. As part of recommendations, an intervention program would be designed.

\section{METHODS}

\section{Research Design}

The Descriptive-correlational analysis was utilized. Descriptive analyzes were provided for the respondent's profile and the involvement in physical activities. Correlational analyzes were used to find the relationship between and among parents, teacheres, coaches, peer modelling and children's involvement in physical activities.

The researcher chose the correlational design to satisfy these research hypotheses:

Ho: 1 . There is no significant relationship between parents, teachers, coaches, peer modelling and children's involvement in physical activities 
Also, the Likert Scale was utilized in measuring the level of self-reported responses of the pupils' continuous values are obtained. Inferential statistics were also employed in the current study to determine whether there exists a significant relationship between the variables.

\section{Respondents of the Study}

Two hundred (200) pupils were randomly selected to serve as respondents in this study, those actively participating in physical activities $[\mathrm{PA}]$ inside and outside school. Pupil-respondents were the Grade 1 to 6 pupils in randomly selected private and public schools in the Division of Iligan City, during the school year 2018-2019.

\section{Sampling Procedure}

Simple random sampling was used in the study as the target population of pupil-respondents were randomly selected from these randomly selected private and public schools in the Iligan City Division, Iligan City, Philippines:

\section{Research Instrument}

The survey questionnaires were in structured and closed-ended design to ascertain the respondents' response using a four-point Likert scale with the following options: strongly disagree, disagree, agree, and strongly agree. Each respondent was asked to choose among these possible sets of answers that would correspond to his or her responses closely representing his/her observation or assessment. The questionnaire was adopted from Muris (2001) Journal of Psychopathology and Behavioral Assessment, 23, 145-149.

The instrument used was appropriate in collecting the necessary information and data that were used in measuring the level of pupils' responses on their observation through parents, teachers, coaches and peer modelling. The format of the questionnaire was in the Likert point scale, where the respondents were given questions about their profile and situations where they could answer from strongly disagree to strongly agree. The first part of the instrument was to gather profile information of the respondents, while the second part was designed to measure the pupil's observation on the degree of their responses.

\section{Procedures in Data Gathering}

A letter request was sent to the Superintendent of Iligan City Division, and the School Heads/ Principals of the public and private schools, requesting authority for the conduct of the study. Included in the letter was asking the names of teacher/coach, and pupil-respondent (Grades 1 to 6 - respondents of the study). Upon approval, the Researcher asked the assistance from family members and friends to serve as research assistants, oriented on the do's and don'ts, techniques, and proper approaches in dealing with pupil-respondents and to the whole process of the data gathering activity.

During the interview, the mother tongue was used in translating difficult English words for better understanding of the questions, and to ensure accurate and honest answers from pupil-respondents. A paper-pencil interview instrument was used, with the Researcher and the assistants doing a simultaneous survey to cope with hectic schedules and to assist the pupil-respondents by checking the boxes corresponding to their chosen answers.

Assurance of strict confidentiality was cited in the letter request, as well as verbally delivered to respondents and authorities in schools. Despite young age, pupil-respondents managed to answer the questions in the survey questionnaire distributed to each one to obtain self-reported responses. The classroom teacher/adviser was there to assist and take charge of the control on pupils' discipline during the conduct of the study.

Words of gratitude were uttered to the pupil-respondents, the teachers, Sports Coach, and peers who were participating actively in the conduct of the research study. The school administrators and the staff in the Department of Education of the Iligan City Division were also thanked for their sincere commitment to cooperate with the researcher and the assistants while conducting the research work.

After the respondent finished answering the questionnaire, the researcher and/or assistant retrieved the instrument from each respondent, ready for turning over to the Statistician. The gathering of data was made easier, with an assurance that the one answering the questions was the respondent himself for herself and there was no question or item unanswered or unattended to. 


\section{Scoring Procedure}

Likert Scale was used in measuring the level of self-reported responses of pupils in continuous values, thus obtained. For intensity, in addition to words, a numerical value was indicated below the descriptive word, to emphasize such intensity, and to assure accurate and honest answers.

The survey questionnaire was structured, and a close-ended design ascertained the respondents' answers using four (4) possible responses in the Likert Scale with the following options: Strongly Disagree, Disagree, Agree, and Strongly Disagree.

All data gathered in the study were summed together and treated as interval scales since there were multiple responses and all statements used the same Likert Scale. Hence, a 4-point Likert Scale was used in scoring the items in the questionnaire as shown in Table 2.

Table 1. The Likert Scale Used to Determine the Level of Models' Influence on the Respondents' Involvement in Physical Activities

\begin{tabular}{lll}
\hline Scales & $\begin{array}{l}\text { Level of Models' Influence on the Respondents' Involve- } \\
\text { ment in Physical Activities }\end{array}$ & Description \\
\hline $3.25-4.00$ & Strongly Agree & Highest Positive Response \\
$2.50-3.24$ & Agree & High Positive Response \\
$1.75-2.49$ & Disagree & Low Positive Response \\
$1.00-1.74$ & Strongly Disagree & Lowest Positive Response \\
\hline
\end{tabular}

\section{Treatment of Gathered Data}

Results of gathered data were analyzed using non-parametric statistical tests Pearson Correlations. Frequency and percentage were also used to represent data in tables particularly in the demographic profile and degree of responses. It was indicated that the following research hypotheses were somehow rejected and accepted; there was no relationship between parental, teacher, peer modeling in children's involvement in physical activities except coach modelling which influenced the Dependent Variable, interpreted by the MSU-IIT Licensed Statistical Software (STATA SE 12).

\section{RESULT AND DISCUSSION}

\section{Children's Involvement in Physical Activities (CIPA) The Type of Physical Activities}

The Type of Physical Activities is presented in Table 2, which is found on page 5. Table 2 shows the total number of respondents, frequency, and percentage distribution of the type of sports and physical activities.

Table 2. Frequency and Percentage Distribution of Respondents' Type of Physical Activities

\begin{tabular}{r|rrr}
$\begin{array}{r}\text { Typeofphysi } \\
\text { calActiviti } \\
\text { es }\end{array}$ & Freq. & Percent & Cum. \\
\hline 1 & 36 & 18.00 & 18.00 \\
2 & 18 & 9.00 & 27.00 \\
3 & 22 & 11.00 & 38.00 \\
4 & 19 & 9.50 & 47.50 \\
5 & 6 & 3.00 & 50.50 \\
6 or more & 99 & 49.50 & 100.00 \\
\hline Total & 200 & 100.00 &
\end{tabular}

It could be gleaned in Table 2 that out of the 200 total population of pupil-respondents, most of them, 99 (49.50\%) were engaged in 6 or more physical activities, which were: Basketball, Volleyball, Swimming, Martial Arts, Badminton, Running, and Jogging. It could be implied that with these were the common sports played in the region, and physical activities performed by children were possible with the availability of sports programs and facilities, which could mean that children's engagement increased, while $36(18 \%)$ played only 1 type of PA, to master skills during rehearsals in preparation for athletic games. The remaining $18(9 \%), 22(11 \%), 19(9.5 \%)$, and $6(3 \%)$ performed $2,3,4$, and 5 types of PAs, respectively, not much performance of PAs after school. 


\section{The Frequency of Engagement Per Week}

The Frequency of Engagement Per Week is presented in Table 3, which is found on page 6. Table 3 shows the total number of respondents, frequency, and percentage distribution of the frequency of engagement per week.

Table 3. Frequency and Percentage Distribution of Respondents' Frequency of Engagement Per Week

\begin{tabular}{r|rrr} 
Frequency & Freq. & Percent & Cum. \\
\hline 1 & 51 & 25.50 & 25.50 \\
2 & 14 & 7.00 & 32.50 \\
3 & 27 & 13.50 & 46.00 \\
4 & 25 & 12.50 & 58.50 \\
5 & 20 & 10.00 & 68.50 \\
6 & 51 & 25.50 & 94.00 \\
7 & 12 & 6.00 & 100.00 \\
\hline Total & 200 & 100.00 &
\end{tabular}

Table 3 shows that out of the total population of 200 pupil-respondents, most of them, 51 (25.5\%) had to involve in physical activities [PA] in 1 day in biking and swimming during weekends, and another 51 (25.5\%) performed in 6 days during elimination rounds for selection of athletes who would qualify for the annual Division Meet, children's engagement in types of PAs were affected by the upcoming school participation.

It could also be implied that 14 (7\%), 27 (13.4\%), 25 (12.50\%), $20(10 \%)$, and $12(6 \%)$ of them performed in 2, 3, 4, 5, and 7 days in PAs when practicing for the upcoming Division Meet, rigid training done by sports coach to prepare the children in competition games, referring to Wiese-Bjornstal et al., (2009) in the context of sports participation, where important developmental considerations are evident. Active play is essential for the child to get rid of the surplus energy (Curtis, 1915; Coleman \& Sebire, 2017) where animal or child does not need to expend all energy in obtaining food, shelter, or gaining a living, that the leftover energy would be used for play.

\section{The Intensity of Exercise}

The Intensity of Exercise is presented in Table 4, which is found on page 6 . Table 4 shows the total number of respondents, frequency, and percentage distribution of the intensity of exercise.

Table 4. Frequency and Percentage Distribution of Respondents' Intensity of Exercise

\begin{tabular}{r|rrr} 
Intensity & Freq. & Percent & Cun. \\
\hline Low & 48 & 24.00 & 24.00 \\
Moderate & 37 & 18.50 & 42.50 \\
High & 32 & 16.00 & 58.50 \\
Vigoorous & 83 & 41.50 & 100.00 \\
\hline Total & 200 & 100.00 &
\end{tabular}

Table 4 shows that out of the total population of 200 pupil-respondents, most of them, 83 (41.50\%) engaged vigorously in physical activities [PA], the intensity of exercise parallel to Morris' (2016) study results on vigorous-intensity promoting pupils' fitness, in this study, however, children involved in vigorous activities were those who played during elimination rounds, and when qualified to become official players, had practiced vigorously with the sports coach.

On the other hand, it could also mean that 48 (24\%) engaged in low intensity of PA, 37 (18.5\%), and $32(16 \%)$ engaged low, moderate, and high intensity of PA was not included as official players rehearsing for the upcoming Division Meet, but they performed PAs during physical education classes, and for fun with peers, and during weekends in other places. It could also mean that children performed PAs in the context of gender socialization where boys engage in PAs with boys, and girls 
perform PAs with girls (Lytton \& Romney, 1991), not with much intensity, but for fun and relaxation.

\section{The Time Spent on the Chosen Physical Activities}

The Time Spent on the Chosen Physical Activities is presented in Table 5, which is found on page 7 . Table 5 shows the total number of respondents, frequency, and percentage distribution of the time spent on the chosen physical activities (in minutes).

Table 5. Frequency and Percentage Distribution of Respondents' Time Spent on the Chosen Physical Activities (in minutes)

\begin{tabular}{r|rrr} 
Time & Freq. & Percent & Cum. \\
\hline 14 & 2 & 1.00 & 1.00 \\
15 & 26 & 13.00 & 14.00 \\
20 & 2 & 1.00 & 15.00 \\
30 & 34 & 17.00 & 32.00 \\
60 & 18 & 9.00 & 41.00 \\
120 & 118 & 59.00 & 100.00 \\
\hline Total & 200 & 100.00 &
\end{tabular}

Table 5 shows that out of the total population of 200 pupil-respondents, most of them, 118 (59\%) spent 120 minutes or 2 hours on their chosen physical activities [PA], these are children who participated in the elimination rounds and when qualified, were part of the practicing team, preparing for the annual Division Meet participation. It could be implied further that athletes, at the micro-systemic developmental level, the origin and the development of the sport-related capacities are affected by a complex interplay among genetic contributions, social climates, and physical environments (Brewer, 2009), most specifically by the influence of the sports coach facilitating rehearsals in rigid rehearsals

Meanwhile, $34(17 \%)$ spent 30 minutes, $26(13 \%)$ spent 15 minutes, while $2(1 \%)$ and another $2(1 \%)$ spent only 14 and 20 minutes in PA. This could mean that these children were not part of the team selected to do rehearsals in preparation for the upcoming annual Division Meet, referring to Hartup's (Mussen \& Hetherington, 1983) afterschool programs that include opportunities for outdoor free play.

\section{The Modelling Influence on Children's Involvement in Physical Activities [CIPA] Parents' Mod- elling Influence on CIPA}

Parents' modelling influence is presented in Table 6 , which is found on page 8 . Table 6 shows the total number of respondents, frequency, and percentage distribution of the parents' modelling influence to CIPA.

Table 6. Frequency and Percentage Distribution of Parents' Modelling Influence on CIPA

\begin{tabular}{r|rrr} 
Parent & Freq. & Percent & Cum. \\
\hline Strong Disagree & 4 & 2.00 & 2.00 \\
Disagree & 42 & 21.00 & 23.00 \\
Agree & 123 & 61.50 & 84.50 \\
Strongly Agree & 31 & 15.50 & 100.00 \\
\hline Total & 200 & 100.00 &
\end{tabular}

Table 6 shows that out of the total population of 200 pupil-respondents, most of them, adding up 'strongly agree' and 'agree' $154(77 \%)$ said that their parents had influenced their involvement in physical activities [PA], while only $46(23 \%)$ said that their parents did not influence them which could mean contention that exercise should be made fun as parents do, as exercise model Feldman's (1981). 


\section{Teacher Modelling Influence on CIPA}

Teachers' modelling influence is presented in Table 7, which is found on page 8. Table 7 shows the total number of respondents, frequency, and percentage distribution of the teacher modelling influence to CIPA.

Table 7. Frequency and Percentage Distribution of Teachers' Modelling Influence on CIPA

\begin{tabular}{r|rrr} 
Teacher & Freq. & Percent & Cum. \\
\hline Strong Disagree & 11 & 5.50 & 5.50 \\
Disagree & 71 & 35.50 & 41.00 \\
Agree & 99 & 49.50 & 90.50 \\
Strongly Agree & 19 & 9.50 & 100.00 \\
\hline Total & 200 & 100.00 &
\end{tabular}

Table 7 shows that out of the total population of 200 pupil-respondents, 118 (59\%) 'strongly agreed' and 'agreed that their teachers influenced their involvement in physical activities [PA]. On the other hand, only $82(41 \%)$ stated that their teachers did not influence their involvement in PAs. It could be implied that children's involvement in physical activities is not largely influenced by teachers, parallel to Morris' (2016) study results despite the utilization of Physical Education grades as participation scores, while Parten's (1932) findings revealed that the child is not playing but watches anything that happens to catch his interest. The child may play with his or her own body, move around, remain in one location, or follow a teacher, this explains the theory of Unoccupied Play.

\section{Coach Modelling Influence on CIPA}

Coach modelling influence is presented in Table 8 , which is found on page 9 . Table 8 shows the total number of respondents, frequency, and percentage distribution of the coach modelling influence to CIPA.

Table 8. Frequency and Percentage Distribution of Coach Modelling Influence on CIPA

\begin{tabular}{r|rrr} 
Coach & Ereq. & Percent & Cum. \\
\hline Strong Disagree & 6 & 3.00 & 3.00 \\
Disagree & 17 & 8.50 & 11.50 \\
Agree & 119 & 59.50 & 71.00 \\
Strongly Agree & 58 & 29.00 & 100.00 \\
\hline Iotal & 200 & 100.00 &
\end{tabular}

Table 8 shows that out of the total population of 200 pupil-respondents, most of them, 177 stated that their coach coaches influenced them to involve in physical activities [PA], while $23(11.5 \%)$ said that their coach did not influence them, which could mean that once coach's manifest sports enthusiasm, children are likely to emulate engagement (Huang et al., 2021).

\section{Peer Modelling Influence on CIPA}

Peer Modelling influence is presented in Table 9, which is found on page 9. Table 9 shows the total number of respondents, frequency, and percentage distribution of the peer modelling influence to CIPA. 
Table 9. Frequency and Percentage Distribution of Peer Modelling Influence on CIPA

\begin{tabular}{r|rrr} 
Peer & Freq. & Percent & Cum. \\
\hline Strong Disagree & 4 & 2.00 & 2.00 \\
Disagree & 29 & 14.50 & 16.50 \\
Agree & 124 & 62.00 & 78.50 \\
Strongly Agree & 43 & 21.50 & 100.00 \\
\hline Total & 200 & 100.00 &
\end{tabular}

Table 9 shows that out of the total population of 200 pupil-respondents, most of them, 167 $(83.5 \%)$ stated that their peers influenced their involvement in physical activities [PA], while 33 (16.5\%) said that their peers did not influence their engagement in PA, which could mean that not only family but also friends and peers can guide behaviors (Maturo, 2004), also referring to Kohlberg's Moral Development Theory, stage 2, where children are self-interest driven, that if they belong to a group, they have the 'what-is-it-for-me' position where right behavior is defined by whatever the individual believes to be in the best interest.

\section{Relationship Between the Models and CIPA}

Relationship between the Parents', Teacher, Coach, Peer Modelling and (CIPA) Type of Physical Activities, Frequency of Engagement Per Week, Intensity of Exercise and Time Spent on the Chosen Physical Activities were determined.

\section{Relationship Between Parents' Modelling and CIPA}

The relationship between parents' modelling to CIPA; type of physical activity, frequency of engagement, intensity of exercise, and time spent in the chosen physical activity.

\section{Relationship Between Parents' Modelling and Type of Physical Activities}

The relationship between parents' modelling and type of physical activities is presented in Table 10 , which is found on page 10 . Table 10 shows the total number of respondents and the relationship between parents' modelling and type of physical activities.

Table 10. Relationship Between Parents' Modelling and Type of Physical Activities

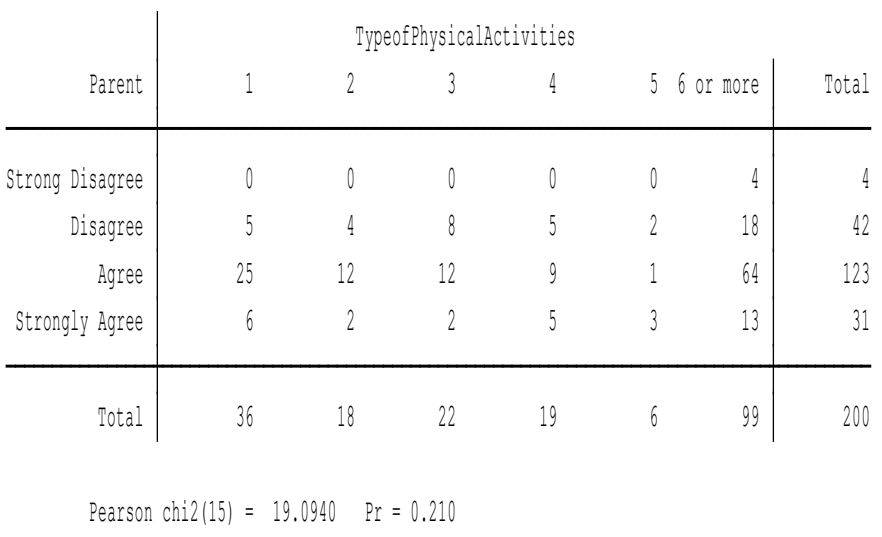

Table 10 reveals that out of the total population of 200 pupil-respondents, although most of them (154) strongly agreed that their parents mattered as to the type of physical activities, but $\operatorname{Pr}=0.210$ was evident that there was no significant relationship between parents' modelling and the type of physical activities [PA]. It could mean that although in the results, pupil-respondents said that their parents influenced the type of PA, but it had no significant relationship because children could have different interests from their parents' interests, or they had similar interests with friends. It could 
be implied in these results that not only schools but parents as well could influence the type of activities children to engage in (Feldman, 1981).

\section{Relationship Between Parents' Modelling and Frequency of Engagement Per Week}

The relationship between parents' modelling and frequency of engagement per week is presented in Table 11, which is found on page 10. Table 11 shows the total number of respondents and the relationship between parents' modelling and frequency of engagement per week.

Table 11. Relationship Between Parents' Modelling and Frequency of Engagement Per Week

\begin{tabular}{|c|c|c|c|c|c|c|c|c|}
\hline \multirow[b]{2}{*}{ Parent } & \multicolumn{8}{|c|}{ Erequency } \\
\hline & 1 & 2 & 3 & 4 & 5 & 6 & 7 & Total \\
\hline Strong Disagree & 2 & 1 & 0 & 0 & 0 & 0 & 1 & 4 \\
\hline Disagree & 12 & 3 & 4 & 6 & 7 & 7 & 3 & 42 \\
\hline Agree & 30 & 9 & 21 & 14 & 11 & 30 & 8 & 123 \\
\hline Strongly Agree & 7 & 1 & 2 & 5 & 2 & 14 & 0 & 31 \\
\hline Total & 51 & 14 & 27 & 25 & 20 & 51 & 12 & 200 \\
\hline
\end{tabular}

Table 11 shows that same with Table 10 results, 154 out of 200 strongly agreed and agreed, $\operatorname{Pr}=0214$ was evident that there was no significant relationship between parent modelling and frequency of engagement. It could mean that parents were influential but because of their work outside homes combined with adult commitments, parents were not present during children's PA, hence not able to serve as model in the frequency of engagement per week. It could be implied in these results that parents influenced not much the frequency of children's engagement per week, but physical activity patterns (Petersen et al., 2020) in each period of time suggests enthusiasm in such engagement.

\section{Relationship Between Parents' Modelling and Intensity of Exercise}

The relationship between parents' modelling and intensity of exercise is presented in Table 12, which is found on page 11 . Table 12 shows the total number of respondents and the relationship between parents' modelling and intensity of exercise.

Table 12. Relationship Between Parents' Modelling and Intensity of Exercise

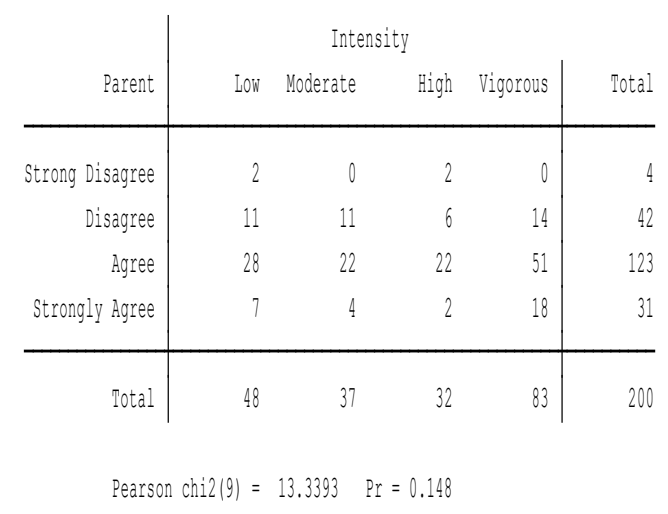

Table 12 shows that out of the total population of 200 pupil-respondents, 154 strongly agreed and agreed, but with $\operatorname{Pr}=0.148$, it could be implied that there was no significant relationship between parent modelling and intensity of exercise. It could mean that children did not see for themselves their parents engaged in PA vigorously, but very busy at work, others were working abroad, while others go home, then fall asleep, while children had too much of surplus energy that needed to be exerted, yet 
they could not observe it in their parents (Curtis, 1915). It could be implied further from these results that parents, having not much influence on the intensity of exercise, could be attributed to the coregulation in Feldman's (1981) observation where children and parents can control behavior, though not true nor so frequent to all.

\section{Relationship Between Parents' Modelling and Time Spent on the Chosen Physical Activities}

The relationship between parents' modelling and time spent on chosen physical activities is presented in Table 13, which is found on page 12. Table 13 shows the total number of respondents and the relationship between parents' modelling and time spent on the chosen physical activities (in minutes).

Table 13. Relationship Between Parents' Modelling and Time Spent on the Chosen Physical Activity

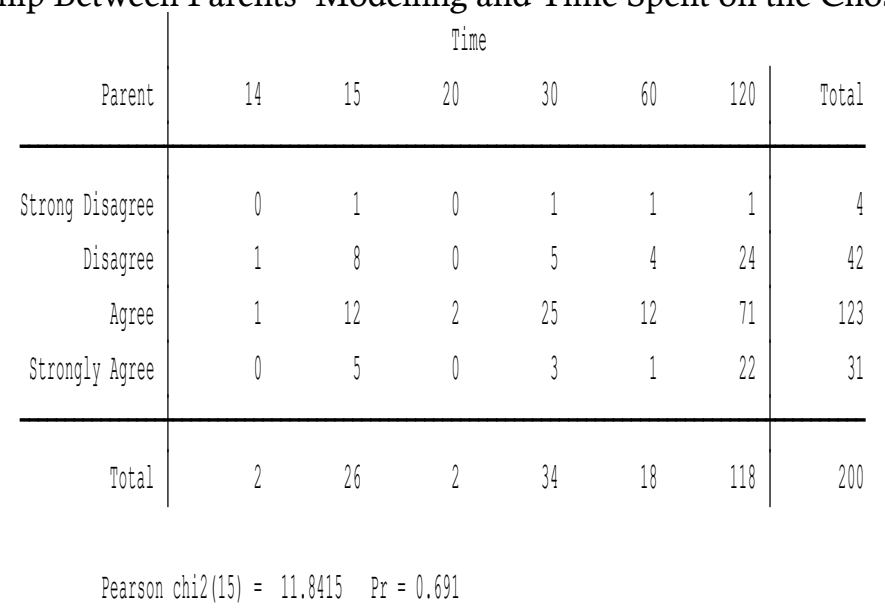

Table 13 shows that out of the total population of 200 pupil-respondents, 154 strongly agreed and agreed, but with $\operatorname{Pr}=0.691$, it was evident that there was no significant relationship between parents modelling and time spent on the chosen PA. It could mean that parents were too busy at work and felt so tired after work, thus chose to do sedentary activities like watching television shows, instead of doing physical activities at home, referring to the Recreation Theory of Mitchell \& Mason, 1948) that focuses on play as a means to recuperate from fatigue experienced from hard work, which means, play restores energy and provides more benefit to the body than idleness.

Thus, Tables 10,11,12, and 13 show that there was no significant relationship between Parents' Modelling and Children's Involvement in Physical Activities.

\section{Relationship Between Teacher Modelling and CIPA}

\section{Relationship Between Teacher Modelling and Type of Physical Activities}

The relationship between teacher modelling and type of physical activities is presented in Table 14 , which is found on page 12. Table 14 shows the total number of respondents and the relationship between teacher modelling and type of physical activities. 
Table 14. Relationship Between Teacher Modelling and Type of Physical Activities

\begin{tabular}{|c|c|c|c|c|c|c|c|}
\hline \multirow[b]{2}{*}{ Teacher } & \multicolumn{6}{|c|}{ Thpe of Phys ic alactivities } & \multirow[b]{2}{*}{ Total } \\
\hline & 1 & 2 & 3 & 4 & 5 & 6 or more & \\
\hline Strong Disagree & 2 & 2 & 2 & 1 & 0 & 4 & 11 \\
\hline Disagree & 9 & 6 & 10 & 5 & 2 & 39 & 71 \\
\hline Agree & 19 & 10 & 9 & 13 & 3 & 45 & 99 \\
\hline St rongly agree & 6 & 0 & 1 & 0 & 1 & 11 & 19 \\
\hline Total & 36 & 10 & 22 & 19 & 6 & $9 y$ & 200 \\
\hline
\end{tabular}

Table 14 shows that out of the total population of 200 pupil-respondents, 118 strongly agreed and agreed, but with $\operatorname{Pr}=0.543$, it was evident there was no significant relationship between the teacher modelling and the type of PA. It could be implied that not all teachers are physically active because not all are physical educators, some are science, mathematics, social sciences, and general education teachers, referring to Vazou's et al., (2012) assertion that observational learning is most powerful when the person being observed is respected or considered to be second parents in school.

\section{Relationship Between Teacher Modelling and Frequency of Engagement Per Week}

The relationship between teacher modelling and frequency of engagement per week is presented in Table 15, which is found on page 13. Table 15 shows the total number of respondents and the relationship between teacher modelling and frequency of engagement per week.

Table 15. Relationship Between Teacher Modelling and Frequency of Engagement Per Week

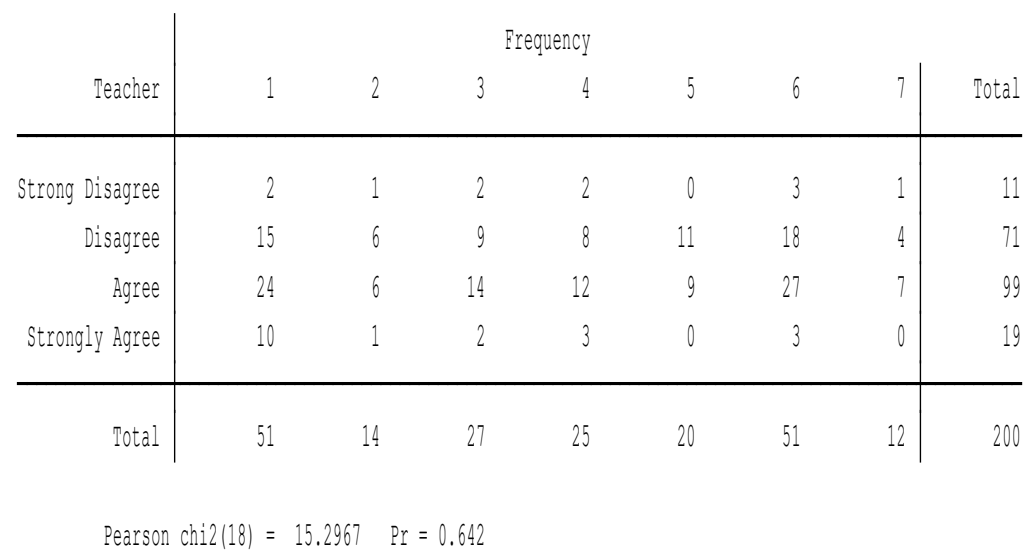

Table 15 shows that out of the total population of 200 pupil-respondents, 118 strongly agreed and agreed, but with $\operatorname{Pr}=0.642$, it was evident that there was no significant relationship between the teacher modelling and frequency of engagement per week. It could be implied that due to the voluminous work of the teacher in school, children could not see the teachers as models in the frequency of engagement. Aside from teachers' non-engagement in PA, they had to perform paper works, attended meetings, conferences, not related to CIPA, referring to Bronfenbrenner's Bioecological Systems Theory that a child's biology is a primary environment fueling his or her development along with the surroundings, like school, community, and the environment (Feldman, 1998). 
Relationship Between Teacher Modelling and Intensity of Exercise

The relationship between teacher modelling and intensity of exercise is presented in Table 16, which is found on page 14 . Table 16 shows the total number of respondents and the relationship between teacher modelling and intensity of exercise.

Table 16. Relationship Between Teacher Modelling and Intensity of Exercise

\begin{tabular}{|c|c|c|c|c|c|}
\hline \multirow[b]{2}{*}{ Teacher } & \multicolumn{4}{|c|}{ Intensity } & \multirow[b]{2}{*}{ Total } \\
\hline & Low & Moderate & High & Vigorous & \\
\hline Strong Disagree & 2 & 1 & 4 & 4 & 11 \\
\hline Disagree & 15 & 17 & 14 & 25 & 71 \\
\hline Agree & 22 & 15 & 13 & 49 & 99 \\
\hline Strongly Agree & 9 & 4 & 1 & 5 & 19 \\
\hline Total & 48 & 37 & 32 & 83 & 200 \\
\hline
\end{tabular}

Table 16 shows that out of the total population of 200 pupil-respondents, 118 strongly agreed and agreed, but with $\operatorname{Pr}=0.070$, it was evident that there was no significant relationship between the teacher modelling and intensity of exercise.

\section{Relationship Between Teacher Modelling and Time Spent on the Chosen Physical Activities}

The relationship between teacher modelling and time spent on the chosen PA is presented in Table 17, which is found on page 14 . Table 17 shows the total number of respondents and the relationship between teacher modelling and PA.

Table 17. Relationship Between Teacher Modelling and Time Spent on the Chosen Physical Activities

\begin{tabular}{|c|c|c|c|c|c|c|c|}
\hline Teacher & 14 & 15 & 20 & 30 & 60 & 120 & Motal \\
\hline Strong Disagree & 0 & 1 & 1 & 1 & 0 & 8 & 11 \\
\hline Disagree & 0 & 9 & 1 & 10 & 8 & 43 & 71 \\
\hline Agree & 2 & 8 & 0 & 19 & 9 & 61 & 99 \\
\hline Strongly Agree & 0 & 8 & 0 & 4 & 1 & 6 & 19 \\
\hline Total & 2 & 26 & 2 & 34 & 18 & 118 & 200 \\
\hline
\end{tabular}

Table 17 shows that out of the total population of 200 pupil-respondents, 118 strongly agreed and agreed, and with $\operatorname{Pr}=0.010$ was evident that there was a significant relationship between the teacher modelling and time spent on the chosen PA. It could mean that children performed sports and physical activities were aspiring for grades while spending time for the chosen sports and physical activities (Morris, 2016), to earn participation scores. 


\section{Relationship Between Coach Modelling and Type of Physical Activities}

The relationship between coach modelling and type of PA is presented in Table 18, which is found on page 15. Table 18 shows the total number of respondents and the relationship between coach modelling and type of sports and physical activities.

Table 18. Relationship Between Coach Modelling and Type of Physical Activities

\begin{tabular}{|c|c|c|c|c|c|c|c|}
\hline \multirow[b]{2}{*}{ Coach } & \multicolumn{7}{|c|}{ TypeofPhysicalActivities } \\
\hline & 1 & 2 & 3 & 4 & 5 & 6 or more & Total \\
\hline Strong Disagree & 0 & 0 & 0 & 0 & 0 & 6 & 6 \\
\hline Disagree & 0 & 1 & 3 & 3 & 0 & 10 & 17 \\
\hline Agree & 22 & 9 & 10 & 7 & 3 & 68 & 119 \\
\hline Strongly Agree & 14 & 8 & 9 & 9 & 3 & 15 & 58 \\
\hline Total & 36 & 18 & 22 & 19 & 6 & 99 & 200 \\
\hline
\end{tabular}

Table 18 shows that out of the total population of 200 pupil-respondents, 177 strongly agreed and agreed, and with $\operatorname{Pr}=0.013$, it was evident that there was a significant relationship between coach modelling and type of PA the respondents' coach engaged to, with data showing that coach modelling was related to the type of physical activities. It could mean that due to the coach' nature of work of being players' trainer, the coach had modelled the type of physical activity, that coach was actively engaged, plus the coach physique capable of performing PA, referring to Huang et al. (2021) findings that coach manifest sports enthusiasm, then children were likely to emulate engagement.

\section{Relationship Between Coach Modelling and Frequency of Engagement Per Week}

The relationship between coach modelling and frequency of engagement per week is presented in Table 19, which is found on page 15. Table 18.2 shows the total number of respondents and the relationship between coach modelling and frequency of engagement per week.

Table 19. Relationship Between Coach Modelling and Frequency of Engagement Per Week

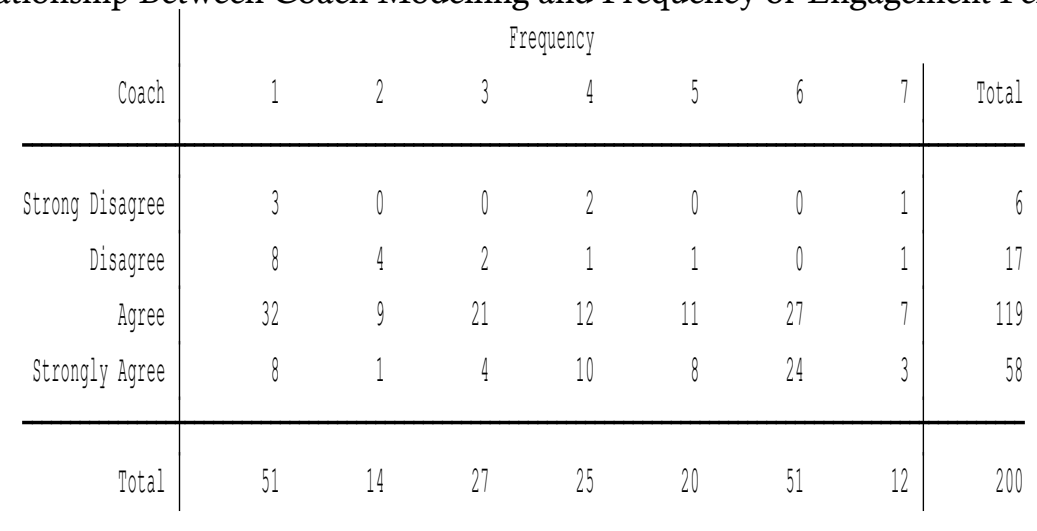

Pearson chi2 (18) $=40.6159 \quad \mathrm{Pr}=0.002$

Table 19 shows that out of the total population of 200 pupil-respondents, 177 strongly agreed and agreed, and with $\operatorname{Pr}=0.002$, it was evident that there was a significant relationship between coach modelling and frequency of engagement per week. It could be implied that coach could not perform his job if he was not physically capable of doing so, referring to Telford et al. (2021) findings that at- 
titudes, values, new ways of thinking were modelled by children on their coach influence.

\section{Relationship Between Coach Modelling and Intensity of Exercise}

The relationship between coach modelling and intensity of exercise is presented in Table 20, which is found on page 16. Table 20 shows the total number of respondents and the relationship between coach modelling and intensity of exercise.

Table 20. Relationship Between Coach Modelling and Intensity of Exercise

\begin{tabular}{r|rrrr|r}
\multirow{2}{*}{ Coach } & \multicolumn{5}{|c|}{ Intensity } \\
& Low & Moderate & High & Vigorous & Total \\
\hline Strong Disagree & 3 & 2 & 1 & 0 & 6 \\
Disagree & 7 & 7 & 2 & 1 & 17 \\
Agree & 31 & 19 & 23 & 46 & 119 \\
Strongly Agree & 7 & 9 & 6 & 36 & 58 \\
\hline Total & 48 & 37 & 32 & 83 & 200 \\
\multicolumn{2}{|c|}{ Pearson chi2 $(9)=29.5660$} & Pr $=0.001$
\end{tabular}

Table 20 shows that out of the total population of 200 pupil-respondents, 177 strongly agreed and agreed, and with $\operatorname{Pr}=0.001$, it was evident that there was a significant relationship between the coach modelling and the intensity of exercise. It could mean that coach had modelled CIPA, that the nature of his or her work involved physical activities, referring to Recreation Theory (Mitchell \& Mason, 1948) on physical activity to restore energy and ways to recuperate from fatigue and hard work, the only way was to play for diversion, and for fun.

\section{Relationship Between Coach Modelling and Time Spent on the Chosen Physical Activities}

The relationship between coach modelling and time spent on the chosen PA is presented in Table 21 , which is found on page 16 . Table 21 shows the total number of respondents and the relationship between coach modelling and time spent on the chosen physical activities.

Table 21. Relationship Between Coach Modelling and Time Spent on the Chosen Physical Activities

\begin{tabular}{r|rrrrrr|r} 
Coach & 14 & 15 & 20 & 30 & 60 & 120 & Total \\
\hline Strong Disagree & 0 & 1 & 0 & 2 & 0 & 3 & 6 \\
Disagree & 1 & 6 & 1 & 2 & 4 & 3 & 17 \\
Agree & 0 & 15 & 1 & 25 & 12 & 66 & 119 \\
Strongly Agree & 1 & 4 & 0 & 5 & 2 & 46 & 58 \\
\hline Total & 2 & 26 & 2 & 34 & 18 & 118 & 200 \\
Pearson chi2 (15) = & 39.2895 & Pr $=0.001$ & & & &
\end{tabular}

Table 21 shows that out of the total population of 200 pupil-respondents, 177 strongly agreed and agreed, and with $\operatorname{Pr}=0.001$, it was evident that there was a significant relationship between the coach modelling and the time spent on the chosen PA. It could be implied that due to the school's preparation for the upcoming Annual Division Meet, CIPA needed a long period of training, at the same time, enjoyed the games, referring to Vazou's et al., (2012) findings that observational learning is most powerful when the person being observed is influential, like the coach being looked up to by the trainees, the children. 
Thus, Table 18, 19, 20, and 21 show that there was a significant relationship between coach modelling and children's involvement in physical activities.

\section{Relationship Between Peer Modelling and Type of Physical Activities}

The relationship between peer modelling and type of PA is presented in Table 22, which is found on page 17. Table 22 shows the total number of respondents and the relationship between peer modelling and type of physical activities.

Table 22. Relationship Between Peer Modelling and Type of Physical Activities

\begin{tabular}{|c|c|c|c|c|c|c|c|}
\hline \multirow[b]{2}{*}{ Peer } & \multicolumn{7}{|c|}{ TypeofPhysicalactivities } \\
\hline & 1 & 2 & 3 & 4 & & & Motal \\
\hline Strong Disagree & 1 & 0 & 0 & 0 & 0 & 3 & 4 \\
\hline Disagree & 4 & 3 & 5 & 6 & 2 & 9 & 29 \\
\hline Agree & 23 & 12 & 15 & 9 & 2 & 63 & 124 \\
\hline Strongly Agree & 8 & 3 & 2 & 4 & 2 & 24 & 43 \\
\hline Total & 36 & 18 & 22 & 19 & 6 & 99 & 200 \\
\hline
\end{tabular}

Table 22 shows that out of the total population of 200 pupil-respondents, 167 strongly agreed and agreed, but with $\operatorname{Pr}=0.464$, it was evident that there was no significant relationship between the peer modelling and type of physical activities. It could mean that although peers were friends, they had different kinds of sports engaged in. Although their parents were also friends, they did not have the same type of sports and physical activities, referring to 'Unoccupied Play' (Parten, 1932) where children were not playing but watched anything that happened to catch their interest.

\section{Relationship Between Peer Modelling and Frequency of Engagement Per Week}

The relationship between peer modelling and frequency of engagement per week is presented in Table 23, which is found on page 18. Table 23 shows the total number of respondents and the relationship between peer modelling and frequency of engagement per week.

Table 23. Relationship Between Peer Modelling and Frequency of Engagement Per Week

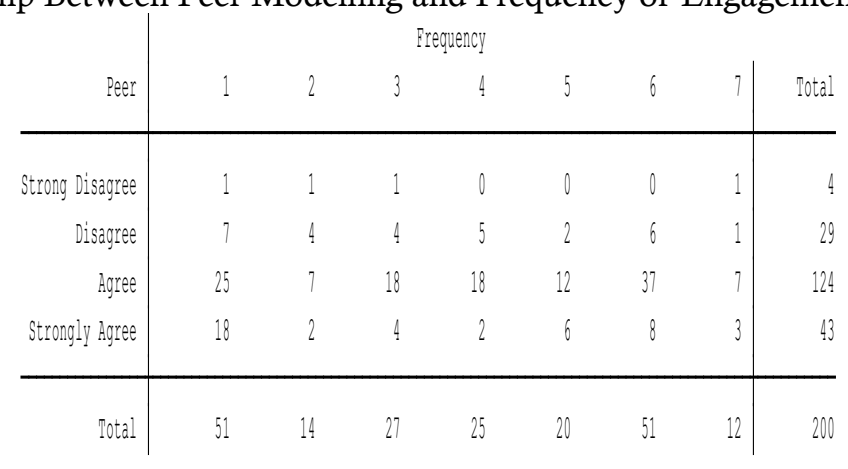

Pearson chi2 $2181=22.1224 \quad p_{r}=0.227$

Table 23 shows that out of the total population of 200 pupil-respondents, 167 strongly agreed and agreed, but with $\operatorname{Pr}=0.464$, it was evident that there was no significant relationship between the peer modelling and the frequency of engagement per week. It could mean that because of their young age, children were not allowed to go out from homes to be with peers in performing PA, but they 
were able to play with peers while practicing for the Annual Division Meet preparations, referring to Instinct Theory (Curtis, 1915), that play is inherited and that the child was engaged in behaviors and activities instinctively, despite the limited days to play within the week.

\section{Relationship Between Peer Modelling and Intensity of Exercise}

The relationship between peer modelling and intensity of exercise is presented in Table 24, which is found on page 18 . Table 24 shows the total number of respondents and the relationship between peer modelling and intensity of exercise.

Table 24. Relationship Between Peer Modelling and Intensity of Exercise

\begin{tabular}{r|rrrr|r} 
& \multicolumn{5}{|c}{ Intensity } \\
Peer & Low & Hoderate & High & Vigorous & Total \\
\hline Strong Disagree & 2 & 0 & 1 & 1 & 4 \\
Disagree & 5 & 11 & 5 & 8 & 29 \\
Agree & 24 & 19 & 20 & 61 & 124 \\
Strongly Agree & 17 & 7 & 6 & 13 & 43 \\
\hline Total & 48 & 37 & 32 & 83 & 200 \\
\multicolumn{2}{|c|}{ Pearson chi2 $(9)=19.6108$} & $\mathrm{Pr}=0.020$
\end{tabular}

Table 24 shows that out of the total population of 200 pupil-respondents, only 33 strongly disagreed and disagreed, while most of the respondents, 167 strongly agreed and agreed, and with $\operatorname{Pr}=0.020$, it was evident that there was a significant relationship between the peer modelling and intensity of exercise. It could be implied that children had modelled their peers despite the different types of activities, but when children observed their peers playing with intensity, then, children would be influenced to do the same vigorous activity, referring to Kohlberg's Theory of Moral Development, where children aging from 10 to 11 years, undergo shifts, younger children base their moral judgments more on consequences, whereas older children base their judgments on intentions (Kutnick, 2012).

\section{Relationship Between Peer Modelling and Time Spent on the Chosen Physical Activities}

The relationship between peer modelling and time spent on the chosen PA is presented in Table 25 , which is found on page 19 . Table 25 shows the total number of respondents and the relationship between peer modelling and time spent on the chosen sports and physical activities.

Table 25. Relationship Between Peer Modelling and Time Spent on the Chosen Physical Activities

\begin{tabular}{r|rrrrrr|r} 
& \multicolumn{7}{|c}{ Time } \\
Peer & 14 & 15 & 20 & 30 & 60 & 120 & Total \\
\hline Strong Disagree & 0 & 0 & 0 & 1 & 0 & 3 & 4 \\
Disagree & 1 & 4 & 1 & 3 & 3 & 17 & 29 \\
Agree & 1 & 8 & 1 & 23 & 14 & 77 & 124 \\
Strongly Agree & 0 & 14 & 0 & 7 & 1 & 21 & 43 \\
\hline Total & 2 & 26 & 2 & 34 & 18 & 118 & 200 \\
\multicolumn{2}{|c|}{ Pearson chi2 (15) $=27.2784$} & $\operatorname{Pr}=0.027$ & & & &
\end{tabular}

Table 25 shows that out of the total population of 200 pupil-respondents, 167 strongly agreed and agreed, and with $\operatorname{Pr}=0.027$, it was evident that there was a significant relationship between the peer modelling and time spent on the chosen PA. It could mean that without their parents or guardians company, children were not able to go out and perform PA, but they played only in schools during school days, or weekends. Although children are naturally playful, referring to Surplus Energy Theory 
that children having cathartic energy, as a powerful tool of accessing and releasing pent of emotions (Curtis, 1915).

\section{CONCLUSION}

Given the foregoing results and discussions, it could be concluded that most pupil-respondents were on the sporting age from 10 to 12 years of age, on the higher percentage of males involved in physical activities [PA] over females, considering their physique, but not much difference compared to females' engagement also in PA (101 males, 99 females). Most of the respondents were generally healthy as they were actively involved in physical activities, also belonging to 'above average and average socio-economic status', able to take vitamins and energy boosters because their parents could provide them on their needs. These were beneficial to the CIPA, more so their parents were able to provide physical activities supplies, materials, and equipment to support active engagement in PA.

It could be concluded further that parents, teachers, coaches, and peer modelling were all influential to CIPA, proving that Bronfenbrenner's Bio-Ecological System was operational on the process, from the nuclear family to the school, community, and farther to the outer systems, CIPA was greatly influenced by such factors, thus their effects on modelling were evident in the study.

However, among all the models, the coach had the closest relationship with the CIPA (type of physical activities, frequency of engagement per week, intensity of exercise, and time spent on the chosen physical activities). Surprisingly, parents who were supposed to be the first models at home, were not that influential on CIPA because they were too busy doing other things at home or outside their homes, definitely not physical activities.

\section{ACKNOWLEDGEMENT}

The researcher is greatly indebted to the following, who had contributed much to the success of this endeavor: Mr. Daniel R. Sanson, a Statistician, whose expertise in the field of statistics, had made this study very scientific. The Iligan City Schools Division Superintendent, School Principals, and Teachers for their generosities in accommodating the conduct of this research work; To Alpha Psi Omega fraternity members who served as Research Assistants and helping hand during the gathering of data.

\section{REFERENCE}

Acero, V.D., Evelyn, S.J. \& Herminia, O.C. 2008. Child and Adolescent Development. Manila: Rex Book Store.

Alberico, C.O., Schipperijn, J. \& Reis, R.S. 2017. Use of Global Positioning System of Physical Activity Research in Youth: ESPACOS Adolescentes, Brazil. Preventive Medicine, 103: 59-65. https://doi.org/10.1016/j.ypmed.2016.12.026

Allen, J.O., Griffith, D.M. \& Gaines, H.C. 2013. "She Looks Out for the Meals, Period" African American Men's Perceptions of How Their Wives Influence Their Eating Behavior and Dietary Health. Health Psychology, 32 (4): 447-455. https://psycnet.apa.org/doi/10.1037/a0028361

Allen, J.B. 2018. Social Motivation in Youth Sport. University of Waikato, Hamilton, New Zealand. Journal of Sport \& Exercise Psychology, 25: 551-567. http://groups.jyu.fi/sporticus/lahteet/LAHDE_5.pdf

Ashford, B., Biddle, S. \& Goudas, M. 1993. Participation in Community Sports Centres: Motives and Predictors of Enjoyment. Journal of Sports Sciences, 11 (3): 249-256. https://doi. org/10.1080/02640419308729992

Bandura, A. 1971. Social Cognitive Theory. New York: General Learning Press. www.asecib.ase.ro/ mps/Bandura_SocialLearningTheory.pdf

Benjamin-Neelon, S.E., Neelon, B., Pearce, J., Grossman, E.R., Gonzales-Nahm, S., Slining, M., Duffey, K. \& Frost, N. 2018. State Regulations Promoting Infant Physical Activity in Early Care and Education. Childhood Obesity, 14 (6): 368-374. https://www.liebertpub. com/doi/pdf/10.1089/chi.2018.0087

Brewer, B.W. 2009. Handbook of Sports Medicine and Science (Psychological Aspects to Central Sports Performance). USA: Wiley- Blackwell Online Books. https://stillmed.olympics.com/ 
media/Document\%20Library/OlympicOrg/IOC/Who-We-Are/Commissions/Medical-andScientific-Commission/Handbooks/2009_Brewer.pdf

Coleman \& Sebire. 2017. Do People's Goals for Mass Participation Sporting Events Matter? A Self Determination Theory Perspective" Research Associate. Journal of Public Health (Oxford), 39 (4): 202-208. https://www.ncbi.nlm.nih.gov.PubMed/27679656/

Coleman, L., Cox, L. \& Roker, D. 2008. Girls and Young Women's Participation in Physical Activity: Psychological and Social Influences. Health Education Research, 23 (4): 633-647. https://doi. org/10.1093/her/cym040

Curtis, H.S. 1915. Education Through Play Early Childhood News. New York: MacMillan.

Efrat, M.W. 2017. Exploring Strategies that Influence Children's Physical Activity. Contemporary Issues in Education Research, 10 (2): 87-94. https://files.eric.ed.gov/fulltext/EJ1137696.pdf

Feldman, Robert S. American Journal of Public Health. 1981.

Feldman, R.S. 2003. Development Across the Life Span - $3^{\text {rd }}$ Edition. New Jersey: Upper Saddle River.

Feldman, S. \& Gehring, T. 1988. Changing Perceptions of Family Cohesion and Power Across Adolescence. Child Development, 59 (4): 1034-1045. https://pubmed.ncbi.nlm.nih.gov/3168612/.

Huang et al. 2021. A Study on the Perceived Positive Coaching Leadership, Sports Enthusiasm, and Happiness of Boxing Athletes. Sustainability, 13 (13): 7199. http://dx.doi.org/10.3390/ su13137199

Kutnick, P. 2012. The Relationship of Moral Judgement and Moral Action: Kohlberg's Theory, Criticism, and Revision. Taylor \& Francis Online.

Lopez, A.E.A., Duran, L.F.P., Cajiao, M.C.R. \& Jimenez, M.P.F. 2017. Active Learning and Action Research Outside Classroom: Engineering with Social Impact. https://papers.ssrn.com/sol3/ papers.cfm?abstract_id $=2965030$

Lytton, H. \& Romney, D.M. 1991. Parents' Differential Socialization of Boys and Girls: A MetaAnalysis. Psychological Bulletin, 109 (2): 267-296. https://psycnet.apa.org/doi/10.1037/00332909.109.2.267

Marmot, M., Allen, J., Bell, R., Bloomer, E. \& Goldblatt, P. 2012. WHO European Review of Social Determinants of Health and the Health Divide. Lancet, 380 (9846): 1011-1029. https://doi. org/10.1016/s0140-6736(12)61228-8

Moore, P.V., Bennett, K. \& Normand, C. 2017. Centre for Health Policy and Management. Trinity College Dublin, Ireland. Social Science and Medicine, 184: 1-14. http://www.tara.tcd.ie/bitstream/handle/2262/80086/Moore\%202017\%20PTD.pdf?sequence $=1$

Morris, W. 2016. Influence of Teacher Participation on Student Fitness and Student Participation in Physical Education. Doctoral Thesis. North Georgia: Walden University.

Mussen, P.H. \& Hetherington, E.M. 1983. Handbook of Child Psychology: Socialization, Personality, and Social Development (pp.103-196). New York: Psychology Press.

National Nutrition Surveillance Center. 2009. Retrieved September 4, 2018.

Pangalangan, R.C. 2011. Looking After Filipino Children. Consuelo Foundation. http://consuelo. org/resources/download/0ade7c2cf97f75d009975f4d720d1fa6c19f4897.pdf

Parten, M.B. 1932. Social Participation among Pre-School Children. The Journal of Abnormal and Social Psychology, 27 (3): 243-269. https://doi.org/10.1037/h0074524

Petersen, T.L., Moller, L.B., Brond, J.C., Jepsen, R. \& Grontved, A. 2020. Association between Parent and Child Physical Activity: A Systematic Review. International Journal of Behavioral Nutrition and Physical Activity, 17 (67): 1-16. https://doi.org/10.1186/s12966-020-00966-z

Peura, P., Viholainen, H., Aro, T., Raikkonen, E., Usher, E.L., Sorvo, R., Klassen, R.M. \& Aro, M. 2018. Specificity of Reading Self Efficacy among Primary School Children. The Journal of Experimental Education, 87 (4): 1-21. http://dx.doi.org/10.1080/00220973.2018.1527279

Rickwood, G. 2015. The Status of Daily Physical Activity in Northern Ontario's Elementary Public Schools. Journal of Education and Training Studies, 3 (2): 136-149. https://files.eric. ed.gov/fulltext/EJ1054964.pdf

Sison et al. 2018. Prevalence of Cardiovascular Risk Factors in Relation to Socio-Demographic Profile of the Life Course Study in Cardiovascular Disease Epidemiology Study (LIFECARE) Philippine Cohort. Acta Medica Phillippina, 48 (2): 62-69. https://doi.org/10.47895/amp.v48i2.1165

Telford, R.M., Olive, L.S. \& Telford, L.D. 2021. A Peer Coach Intervention in Childcare Centres Enhances Early Childhood Physical Activity: the Active Early Learning (AEL) Cluster Randomised Controlled Trial. International Journal of Behavioral Nutrition and Physical Activity, 18 
(37): 1-11. https://doi.org/10.1186/s12966-021-01101-2

Villar, M. 2020. Statute Governing the Special Protection of Children Against Abuse, Exploitation, and Discrimination Act. $15^{\text {th }}$ Congress of the Republic of the Philippines. Republic Act 7610. https://www/ senate.gov.ph/lisdata/86167171.pdf.

Wiese-Bjornstal, D.M., LaVoi, N.M. \& Omli, J. 2009. Child and Adolescent Development and Sport Participation (in Sport Psychology page 97-112). Wiley-Blackwell Online Books. https://psycnet. apa.org/doi/10.1002/9781444303650.ch10 